\title{
TRAS LAS HUELLAS DEL EMPRESARIO SCHUMPETERIANO: EL CASO DE JOSÉ MARTÍNEZ RIVAS (1872-1913)
}

\author{
PABLO DÍAZ MORLÁN \\ Universidad de Alicante ${ }^{\mathrm{a}}$
}

\begin{abstract}
RESUMEN
Este artículo tiene dos objetivos: analizar la figura empresarial de José Martínez Rivas, protagonista destacado del proceso de industrialización vizcaína, y aplicar herramientas procedentes de la teoría económica para una mejor comprensión de la historia empresarial española. A partir de fuentes de archivo se reconstruye la actividad económica de este hombre de negocios y el destino de su riqueza. El trabajo se divide en tres partes. En el primer apartado se estudia el origen y primeros pasos de las principales iniciativas empresariales que llevó a cabo José Martínez Rivas. En el segundo, se describe la marcha y resultados de cada una de ellas. En el tercero, se emplea la concepción que J. A. Schumpeter tenía de la función empresarial para analizar la actividad de este empresario. Unas conclusiones finales resumen las principales aportaciones del trabajo y abren una puerta a futuras investigaciones relacionadas con el tema tratado y la teoría empleada.
\end{abstract}

Palabras clave: historia empresarial, empresario schumpeteriano, industrialización vizcaína

\section{ABSTRACT}

This article has two objectives: to analyse a leading businessman, José Martínez Rivas, a distinguished leader of Biscayan industrialization, and to apply economic

a Departamento de Análisis Económico Aplicado, Campus de Sant Vicent del Raspeig, Ap. 99, E03080 Alicante, España. pdiaz@ua.es 
theory to his case for a better understanding of Spanish business history. The business life of Martínez Rivas and the evolution of his fortune has been reconstructed with archive sources. The article is divided into three parts. The first section examines the origins and first years of his main business activities. A second section describes the evolution and results in each of these. A third and final part, applies Schumpeterian entrepreneur theory to Martínez Rivas’ business initiatives. The conclusions summarize the main contributions of this work and open a door to further related research and the theory applied.

Keywords: business history, Schumpeterian entrepreneur, Biscayan industrialization

JEL Classification: M13, N83.

\section{INTRODUCCIÓN}

El presente artículo tiene un objetivo doble. Por un lado, se trata de dar los primeros pasos para entender la figura empresarial de José Martínez Rivas, protagonista destacado del proceso de industrialización vizcaína. Por el otro, se pretende aplicar herramientas procedentes de la teoría económica para una mejor comprensión de la historia empresarial española. A partir de fuentes de primera mano he podido reconstruir las claves de la actividad económica de este opulento hombre de negocios y el destino de su riqueza. Los documentos se encuentran en los archivos siguientes: el Foral de Vizcaya -fondos de Altos Hornos de Vizcaya y de Ybarra Hermanos-, el del Marqués de Arriluce, el General de Marina, el Histórico Eclesiástico de Vizcaya, el de la Fundación Antonio Maura, el Histórico de la Provincia de Vizcaya y el de Protocolos de la Provincia de Madrid.

He dividido el trabajo en tres partes. En el primer apartado estudio el origen y primeros pasos de las principales iniciativas empresariales que llevó a cabo José Martínez Rivas. En el segundo describo la marcha y resultados de cada una de ellas. En el tercero empleo la concepción que J. A. Schumpeter tenía de la función empresarial para analizar la actividad de este hombre de negocios, con una triple finalidad: que la historia sirva como campo de pruebas de la teoría económica -en un sentido amplio que incluya la visión dinámica del economista austriaco-; que, a su vez, pueda ser mejor entendida gracias a ella; y que, por último, pueda usarse para mejorarla ${ }^{1}$. Finalmente, unas conclusiones resumen las aportaciones más relevantes del trabajo.

\footnotetext{
${ }^{1}$ De esta forma procuro cumplir con la conocida recomendación schumpeteriana de que se diera un diálogo fluido entre historia y teoría económica. Schumpeter (1968, pp. 255-272).
} 
Se hace necesaria una aclaración sobre el empleo de la teoría de Schumpeter. Le seguiré en su formulación de la función empresarial como exclusivamente definida por la introducción de innovaciones, pero no necesariamente en su convencimiento de que los empresarios constituyen los individuos-causa del desarrollo económi$\mathrm{co}^{2}$. Pienso que es metodológicamente lícita esta selección de elementos de su teoría, desechando unos puntos y adoptando otros, siempre que se haga con el debido cuidado de no caer en contradicciones lógicas ${ }^{3}$. Esta forma de avanzar será además especialmente importante en lo que se refiere al análisis del papel desempeñado por el capital en el proceso de creación de nuevas empresas ${ }^{4}$.

\section{LAS INICIATIVAS EMPRESARIALES DE JOSÉ MARTÍNEZ RIVAS (1872-1894)}

Miguel José Martín Martínez de Lejarza y de las Rivas nació en la localidad vizcaína de Galdames el 29 de septiembre de 1848. Tuvo seis hermanos nacidos entre 1839 y 1860 y sus padres fueron Santiago Martínez de Lejarza Escarzaga (18151888) y Antonia de las Rivas Ubieta (1820-1901), hermana de Francisco de las Rivas, Marqués de Mudela ${ }^{5}$. A mediados de la década de 1850 se trasladaron a vivir a Bilbao, y en la de 1860 José viajó primero a Madrid y después a Londres, a formarse en el escritorio de la firma comercializadora de los vinos de su tío. Francisco de las Rivas, oriundo de Gordejuela (Vizcaya), se había enriquecido en Madrid durante las décadas de 1830 y 1840 como comerciante y banquero y formaba parte del círculo de financieros y especuladores que creció a la sombra del político Juan Álvarez Mendizábal. Tras la crisis de 1848 alteró su actividad empresarial adquiriendo grandes extensiones de terreno provenientes de bienes nacionales en las provincias de Ciudad Real y Toledo, la mayor parte de ellas en el término de Santa Cruz de Mudela, y de ahí el nombre del marquesado que le otorgó Isabel II en 1868. Se enriqueció

\footnotetext{
${ }^{2}$ Es importante dejar esto claro, porque lo que se pretende en este artículo con la utilización del esquema teórico schumpeteriano es analizar la figura histórica del empresario y no explicar el desarrollo económico, que quedaría como un tema aparte del que aquí se trata. Sobre este controvertido punto, véanse Sweezy (1968) y Vence (1995).

${ }^{3}$ Él mismo lo defendió así cuando indicó que su teoría del interés podía ser rechazada o criticada sin que ello impidiera aceptar el esquema global de su teoría del desarrollo económico. Schumpeter (1944).

${ }^{4}$ Emplearé las ediciones en castellano de sus obras: Teoría del desenvolvimiento económico (1944), Ensayos (1968) y Ciclos económicos (2002). Dejando al margen la traducción de algunos conceptos -véase, sobre el de «desenvolvimiento», la crítica de F. Estapé en el prólogo a Ciclos económicos (2002)-, el mayor problema de estas ediciones es que la obra de Schumpeter ha sido cercenada de manera inmisericorde $y$, desde el punto de vista del que esto escribe, no suficientemente justificada. Pero ello no invalida ni distorsiona lo que ha quedado en pie.

${ }^{5}$ AHEV, Galdames, Parroquia de San Pedro Apóstol. Sus hermanos se llamaron Benita, María, Nicolasa, Francisco, Carmen y Serafín. Ver también Conde de Urquijo (1918).
} 
extraordinariamente gracias a la producción y comercialización de los vinos de la zona y la revalorización de algunas de sus otras inversiones. Entró con fuerza en la economía vizcaína en 1879, como luego veremos, y murió en Madrid en 1882, dejando a su único hijo una fortuna valorada en cerca de 70 millones de reales ${ }^{6}$.

Durante su permanencia británica, José casó en 1868 con Augusta Cecilia María Tracy Tool (1847-1879), hija de Martin Tracy, uno de los socios principales del escritorio en que trabajó, y desde 1872 alternó sus estancias en España e Inglaterra, consignando en el Padrón Municipal de Bilbao de 1871 que su residencia habitual era todavía Londres ${ }^{7}$. Demostró una temprana iniciativa en los negocios, ya que con 23 años representó a intereses británicos en la adquisición de un conjunto de minas en Vizcaya de entre las que destacaban Unión y Amistosa, situadas en la mejor zona del criadero de mineral de hierro vizcaíno. Esta exitosa actuación marcó el inicio de su carrera empresarial y también su destino posterior. Entre marzo y noviembre de 1872 se desarrolló el grueso de la complicada operación, en la que sobresalen algunos rasgos que conviene destacar. La figura protagonista de todo el proceso fue el comerciante de Londres George Batters, embarcado en la compra de minas con la mediación de Martínez Rivas. Dio el primer paso el 30 de marzo, cuando José adquirió por su encargo el 40\% de Unión y la totalidad de Amistosa. La primera estaba en manos de siete propietarios que la habían adquirido en 1869, y dos de ellos vendieron su parte a Rivas por 30.000 ptas. Por la segunda se pagaron 183.233 pesetas, que adelantó el cuñado de José, Juan Aburto Azaola, a George Batters, con la garantía de la hipoteca de la mina. El 12 de abril, el mismo Batters adquiría en persona de los Ybarra la cesión por 60 años de las minas San Francisco y Segunda, en Ollargan, a cambio de 250.000 pesetas. En la operación le asistieron como intérpretes Martínez Rivas y otro de los cuñados de éste, Juan Amann Palme ${ }^{8}$. El 20 de julio, era José de nuevo quien adquiría otro 30\% de Unión por encargo de Batters, pagando 22.500 pesetas. Por fin, el 5 de noviembre todas las explotaciones se transfirieron a la Somorrostro Iron Ore, sociedad recién creada por el mismo Batters -que fue nombrado gerente- y otros socios británicos, entre ellos Archelans Tregoning, que incorporó las minas Malaespera y Julia, compradas por él en 1871. En suma, los intereses reunidos en torno a la Somorrostro se hicieron con un importante conjunto de explotaciones vizcaínas, todas ellas productivas, en los años de expansión del

\footnotetext{
${ }^{6}$ Bahamonde y Otero (1989); véanse también Otazu (1987) y Fernández de Pinedo (1988).

${ }^{7}$ En 1874 aparece formando parte del Batallón de Auxiliares durante el sitio de la capital vizcaína, con domicilio en el piso primero del número 15 de la calle Bidebarrieta. Vid. Ruiz de Azúa (1976, p. 278). La información sobre María Tracy se encuentra en Conde de Urquijo (1918) e Ybarra (2002, pp. 565-566).

${ }^{8}$ Juan Amann Palme, nacido en Bilbao en 1830, fue miembro de una conocida familia que participó, entre otras iniciativas, en el Crédito Vasco y en el Ferrocarril de Bilbao a Tudela. Su sobrino José Isaac Amann sería uno de los fundadores de la Sociedad de Terrenos de Neguri. Vid. Galarza (1996, pp. 23 y 44) e Ybarra Ybarra (2002, p. 545).
} 
convertidor Bessemer en Inglaterra9 ${ }^{9}$. Pero su propiedad se transformó con el transcurso del tiempo: entre los años finales de la década de 1870 y 1884, Malaespera, Julia, San Francisco, Segunda y Amistosa pasaron a Rivas, que también se hizo con otro 25\% de Unión, y en 1889 pactó un convenio con la Somorrostro por el cual se comprometía a explotar el $70 \%$ de esa mina por cuenta de la sociedad británica, a cambio de recibir una peseta por tonelada extraída ${ }^{10}$.

Pero el interés inicial de George Batters no se limitó a la exportación del mineral. Desde el principio su pretensión fue la de, al menos en parte, transformarlo en lingote en las cercanías y destinarlo a la exportación. Para ello, al mismo tiempo que compraba las explotaciones, fundó con otros en agosto de 1872 la Cantabrian Iron Company con un capital social de 60.000 libras esterlinas y adquirió por 28.000 a Ciriaco Linares Quintana la finca de San Nicolás del Desierto, en el término municipal de Baracaldo, con el ánimo de convertirla en fábrica siderúrgica mediante la construcción de hornos altos al coque. El precio había sido pactado en Londres en el momento mismo de la constitución de la Cantabrian, y de él se entregaron a Linares 5.000 libras en acciones liberadas de la empresa británica. La operación de compra-venta se efectuó ante un notario de Bilbao el 21 de noviembre de 1872, y quien representó a la Cantabrian fue José Martínez Rivas ${ }^{11}$. Así pues, la Somorrostro Iron Ore y la Cantabrian Iron Company formaron parte del mismo grupo empresarial que, con pretensiones de integración vertical, también adquirió buques para exportar mineral y lingote al Reino Unido, y que tuvo a nuestro empresario como representante exclusivo en Vizcaya ya desde su misma constitución, en el año de 1872.

Sin embargo, la guerra carlista iniciada al año siguiente truncó los ambiciosos planes de Batters. La fábrica en construcción sufrió daños considerables y los ingleses decidieron enajenarla. José, representando a la Cantabrian, la vendió en 1879 a su tío el Marqués de Mudela por 750.000 pesetas y por orden de éste se

${ }^{9}$ La Somorrostro Iron Ore Co. Ltd. estuvo domiciliada primero en Londres y después en Manchester, y su objeto social fue la adquisición de minas en España. Tras su reconstitución en 1879-1880, el capital social quedó establecido en 75.000 libras esterlinas. Véase al respecto Tortella (2000, p. 262).

${ }^{10}$ El restante 5\% de la mina Unión permaneció en manos de un socio minoritario llamado Palacios. Entre enero y febrero de 1885, Rivas vendió a su cuñado Aburto la mina Malaespera por 30.000 pesetas y le arrendó la explotación de San Francisco y Segunda por 200.000. Toda la información acerca de las operaciones efectuadas en torno a las minas se encuentra en los legajos siguientes: AHPV, Serapio Urquijo, leg. 6.237, $\mathrm{n}^{\circ} 155$ y 271; leg. 6.239, $\mathrm{n}^{\circ}$ 369, 389, 390 y 391; Félix Uríbarri, leg. 8.008, $\mathrm{n}^{\circ} 46$ y 47.

${ }^{11}$ Linares había adquirido la finca el 26 de febrero de 1869 a los hermanos José, Mariano y Francisco Zabálburu Basabe, cuya titularidad sobre ella provenía de la desamortización de los bienes eclesiásticos. Los directores de la Cantabrian fueron, además de George Batters, Abraham Darby, Joseph Robinson y Francis Tothill, y el secretario Daniel Norris. AHPV, Serapio Urquijo, 21.11.1872; Félix de Uríbarri, leg. 6.204. 
encargó desde el primer momento de administrarla, finalizando su construcción mediante la canalización de las inversiones del marqués, que ascendieron en los años siguientes a dos millones de pesetas ${ }^{12}$. La nueva San Francisco del Desierto, también conocida como La Mudela, obtuvo ya en 1880 una producción inicial de lingote de 5.782 toneladas, que pasaron a ser 35.974 en 1881 y 30.006 en 1882, mediante el empleo de cuatro hornos altos al coque ${ }^{13}$. La competencia inevitable que iba a surgir entre las empresas siderúrgicas pronto alertó a los Ybarra, principales socios de El Carmen -en aquel momento en plena transformación en Altos Hornos de Bilbao-, que llegaron a plantear la conveniencia de absorber La Mudela, pero la operación no pudo realizarse por la negativa de los Rivas que, al decir de los Ybarra, disfrutaban de elevados beneficios por tres vías diferentes: la venta de lingote, rentas de sus propiedades y el canon pagado por la Diputación de Vizcaya por el transporte de minerales a través de sus tierras ${ }^{14}$. Muy pronto, a finales de la década de 1880, la coyuntura favorable para la exportación de lingote terminó, y el mercado exterior comenzó a declinar. Martínez Rivas trasladó entonces sus esfuerzos al mercado interior de lingote reduciendo precios para poder competir ${ }^{15}$. Y dentro de una estrategia global de integración de actividades, y a la vista del incremento de las tarifas aduaneras para el carbón y el coque británicos en 1891, levantó hornos de coque ese mismo año y adquirió poco después minas en Asturias, creando para ello la sociedad Coto del Musel con un capital de un millón de pesetas ${ }^{16}$.

El primer Marqués de Mudela murió en 1882, y Martínez Rivas siguió dirigiendo la fábrica mientras la propiedad pasaba a manos del segundo Marqués de Mudela, Francisco de las Rivas Urtiaga, hijo del anterior. En 1886, ambos primos firmaron un convenio según el cual el primero se comprometía a comprar al segundo la factoría por el precio de cinco millones de pesetas, a pagar en los quince años siguientes. Pero Francisco falleció sin hijos en 1890 y la herencia se repartió entre sus primos. De esta forma, la titularidad de las instalaciones recayó en los Martínez Rivas, y José pactó con su madre y sus hermanos la apertura de una cuenta de crédito a cada uno por el valor de sus derechos sobre la fábrica. Se hizo así con el control absoluto de la factoría, uniendo en su misma persona la dirección y la propiedad ${ }^{17}$.

\footnotetext{
${ }^{12}$ AHPV, Félix de Uríbarri, leg. 6.204; Bahamonde y Otero (1989, p. 577).

${ }^{13}$ Goenaga (1883, p. 459).

${ }^{14}$ El acuerdo con la Diputación de Vizcaya se encuentra en AHPV, Félix de Uríbarri, leg. 6.204. Ybarra Ybarra (2002, pp. 673-674); Díaz Morlán (2002, pp. 123-124).

${ }^{15}$ Fernández de Pinedo (1987, pp.154-156); Díaz Morlán (2002, p. 126).

${ }^{16}$ Hornos de coque, en Fernández de Pinedo (1997, p. 15). Coll y Sudrià (1987, p. 203) afirman que el Coto del Musel se creó en 1890 con dos millones de capital social, basándose en un trabajo de Rafael Fuertes Arias fechado en 1902, pero Valdaliso (1988, p. 15), cuya fuente es el Registro Mercantil, la sitúa en 1894. Sin embargo, pudiera ser que la sociedad se hubiera creado efectivamente en 1890 y que Rivas la hubiera adquirido cuatro años después.

${ }^{17}$ AHPM, notario Luis González Martínez, 6 de octubre de 1886.
} 
Después de la minería y la siderurgia, Martínez Rivas dio el tercer paso decisivo en la consolidación de su entramado empresarial al convertirse en naviero. Lo hizo tempranamente, al comprar en 1876 a la Somorrostro Iron Ore dos vapores, el Somorrostro y el Fay -luego llamado Desierto-, por 125.000 y 100.000 pesetas respectivamente, mediante su hipoteca en garantía del préstamo que la misma compañía británica le concedió para la operación. El mismo mecanismo fue utilizado por otros navieros, y recuerda al empleado en la adquisición de las minas Unión y Amistosa, e implica, de nuevo, que José no contaba con un capital importante por esas fechas ${ }^{18}$. Un inventario de sus bienes realizado con motivo de la muerte de su esposa, el 13 de diciembre de 1879, demuestra que el capital de Rivas era aún el que podía corresponder a un comerciante mediano del Bilbao de la época, muy lejano todavía de las principales fortunas de la villa. Lo presento resumido en el cuadro siguiente:

\section{CUADRO 1}

\section{INVENTARIO DE JOSÉ MARTÍNEZ RIVAS EN 1879}

\begin{tabular}{|l|c|l|c|}
\hline \multicolumn{1}{|c|}{ Activo } & Pesetas & \multicolumn{1}{|c|}{ Pasivo } & Pesetas \\
\hline Sucursal del Banco de España & 163.674 & Capital & 322.298 \\
Préstamo a sí mismo & 89.077 & Marqués de Mudela & 70.167 \\
Muebles, efectos y alhajas & 50.902 & Compañía Cantabrian Iron Ore & 47.249 \\
Deudores diversos & 46.281 & Acreedores diversos & 32.802 \\
The Campanil Iron Ore & 45.000 & & \\
Préstamos a sus hermanos & 29.596 & & \\
Manuel Allende & 22.722 & & \\
Casas de la Mina Mora (Unión) & 19.894 & & \\
Contratista Malaespera & 5.370 & & $\mathbf{4 7 2 . 5 1 6}$ \\
\hline TOTALACTIVO & $\mathbf{4 7 2 . 5 1 6}$ & TOTAL PASIVO & \\
\hline
\end{tabular}

Fuente: AM, leg. 534/5. La partida «Deudores diversos» aparece en la fuente indicando cada deuda por separado. Lo mismo vale para las partidas «Acreedores diversos» y «Préstamos a sus hermanos».

\footnotetext{
${ }^{18}$ Valdaliso (1991, p. 210). Precisamente como administrador de uno de ellos, el Somorrostro, inició su andadura un personaje que con el tiempo se convertiría en otro de los empresarios más importantes de Vizcaya: Ramón de la Sota y Llano. Martínez Rivas era el dueño del buque, pero Sota lo administró por su cuenta y riesgo, al menos entre agosto de 1884 y febrero de 1886 . Ossa (1969, p. 45); Torres (1998, p. 33).
} 
Descontado el préstamo de 89.077 pesetas hecho a sí mismo, el verdadero capital de Rivas ascendía a 233.220 pesetas, que, junto a las deudas contraídas con la Cantabrian y con su tío soportaban casi la totalidad de un activo difícil de interpretar, pues más de un tercio quedaba englobado bajo el rótulo de Sucursal del Banco de España ${ }^{19}$.

Tras acceder desde 1876 al negocio naviero, en la década de 1880 Rivas sumó sus fuerzas a las de su primo, el segundo Marqués de Mudela, para adquirir tres buques de mayor tonelaje que los dos anteriores, y en 1891, siguiendo una estrategia típica del momento, creó tres sociedades anónimas - una para cada barco-, de las que él mismo se nombró director gerente y a las que asignó como capital social el importe invertido en su compra: 837.000 pesetas para la Compañía del Vapor Mudela, 975.000 para la del Marqués de Mudela y 1.200.000 para la del Rivas ${ }^{20}$. De esos capitales, en el momento de la compra habían correspondido a su primo, el segundo Marqués de Mudela, 355.727, 486.723 y 599.533 pesetas, y a Rivas 266.560, 185.057 y 352.867 pesetas. En el compromiso de 1886 antes mencionado, el marqués acordó vender a su primo sus participaciones, pero su muerte en 1890 convirtió a Rivas y sus hermanos en los dueños absolutos de los buques, por lo que el empresario pactó con ellos la conversión de sus derechos en acciones y préstamos a un interés fijo, mientras él quedaba como propietario y administrador principal, en una operación casi idéntica a la de la fábrica de San Francisco ${ }^{21}$.

La última de aquellas actuaciones más relevantes de Martínez Rivas que dejaron definido su entramado de negocios, fue la que le llevó a convertirse en constructor naval. Las primeras maniobras para instalar en Vizcaya unos astilleros tuvieron un carácter político y comenzaron en mayo de 1887, cuando una fuerte representación de la provincia, en la que participaban tanto la fábrica de San Francisco como la Vizcaya de Víctor Chávarri, visitaron, acompañados de senadores y diputados, a la Reina Regente y a varios ministros en Madrid para pedir que la renovación de la Armada se hiciera contando con las empresas vizcaínas. Fruto de estas gestiones y de otras que vinieron en los meses siguientes fue el decreto de 28 de diciembre de aquel año, que convocó a concurso a aquellas sociedades españolas que estuvieran interesadas en la construcción de los buques de guerra proyectados ${ }^{22}$. Por aquellas mismas fechas, el británico Charles M. Palmer, dueño de un emporio industrial que incluía unos astilleros en Jarrow-on-Tyne, envió a Bilbao, invitado por Martínez Rivas, al ingeniero G. Eldridge para que evaluara las posibilidades de

\footnotetext{
${ }^{19}$ A primera vista, este apartado sería una cuenta en la entidad financiera, de la que sería acreedor Martínez Rivas, pero bien podría representar los valores industriales del empresario custodiados por el banco, lo que obligaría a pensar en una actividad crediticia con esta entidad.

${ }^{20}$ Con 2.300, 2.450 y 4.000 toneladas de carga respectivamente. Echevarría (1900, pp. 3641); Valdaliso (1988, p. 15) y (1991, p. 265).

${ }^{21}$ AHPM, notario Luis González Martínez, 6 de octubre de 1886.

${ }^{22}$ Ybarra Bergé (1947, pp. 123-124).
} 
levantar un astillero ${ }^{23}$. En agosto de 1888, el Consejo de Marina aprobó proponer al Gobierno que otorgara las construcciones a alguna de las tres casas vizcaínas que habían acudido al concurso, y el ejecutivo presidido por Sagasta concedió la parte más importante del convenio, tres grandes cruceros, a la propuesta conjunta de Rivas y Palmer. De inmediato se constituyó la sociedad colectiva Martínez Rivas, Palmer y Compañía, y comenzó a levantarse el astillero, tras haberse firmado el definitivo contrato el 1 de junio de $1889^{24}$.

Rivas proyectó una factoría que contara con muchos de los elementos necesarios para la construcción de los buques, incluidas la maquinaria y la artillería, y contó para ello con la asistencia técnica británica garantizada por el prestigio como constructor naval de su socio, que hizo venir a Bilbao a ingenieros navales y trabajadores cualificados. Palmer cobró por dicha asistencia 42.100 libras esterlinas pactadas en un contrato firmado entre él y Martínez Rivas el 14 de noviembre de 1889, y confiaba en llevarse también el suministro de las máquinas de los cruceros, pero la insistencia del Gobierno en que todo lo necesario para los buques fuera construido en España, tal y como figuraba en el convenio, llevó a Rivas a rescindir el contrato celebrado para tal fin con Palmer \& Co., de Jarrow, y comenzar a levantar sus propios talleres de maquinaria y armamento con el desacuerdo de Palmer. De hecho, la factoría creó grandes expectativas en la prensa y en el mundo de los negocios vizcaínos y fue un probable incentivo para que surgieran empresas metalúrgicas aun antes de la protección instaurada en 1891, ya que tanto la sociedad Aurrerá como la factoría de Alonso Millán y $\mathrm{C}^{\mathrm{a}}$ estaban preparadas para abastecer al astillero de aceros moldeados y piezas de hierro fundido. Rivas informó al interventor de la Marina, además, de que se disponía a levantar un taller de forja destinado a artillería de gran calibre, inexistente hasta entonces en España, que se veía obligada a adquirir los cañones a países extranjeros. Las obras comenzaron ante el entusiasmo de los responsables de Marina, deseosos de lograr la ansiada autonomía española en armamento, pero pronto se paralizaron y las instalaciones quedaron sin terminar debido a una más que probable causa financiera ${ }^{25}$.

El 30 de agosto de 1890 la Reina Regente presidió la ceremonia de botadura del primero de los cruceros, el Infanta María Teresa, y Rivas fue galardonado con la

${ }^{23}$ Rivas, por su parte, entró en conversaciones con Altos Hornos de Bilbao para el suministro de chapa. Vid. Fernández de Pinedo (1997, pp. 9-10) e Ybarra Ybarra (2002, pp. 734-740).

${ }^{24}$ AGM, Astilleros del Nervión, leg. 4.235; Ybarra Bergé (1947, pp. 124-125).

${ }^{25}$ AGM, Astilleros del Nervión, legs. 4.226 y 4.232. Los motivos de la paralización no quedan claros en la documentación consultada, y aunque las estrecheces financieras de Martínez Rivas asoman como la causa más probable, es obligado indicar que el empresario alegó que no se le había permitido importar los elementos necesarios para construir el taller. Esta explicación carecería de toda verosimilitud -dado el interés de la Marina en lograr la fabricación nacional de cañonessi no fuera porque el interventor de la Marina mantuvo una fuerte disputa con el Ministro del ramo en torno a este tema, lo cual demuestra que, en efecto, existieron dificultades. 
Gran Cruz del Mérito Naval. Pero los acontecimientos tomaron pronto un rumbo distinto. Las grandes inversiones requeridas por la factoría llevaron a Rivas a transformar el 5 de enero de 1891 la sociedad colectiva Martínez Rivas, Palmer y Compañía en una sociedad anónima de 30 millones de capital social con el nombre de Astilleros del Nervión. Rivas consiguió así limitar su responsabilidad financiera con respecto a la que había pactado en el convenio con el Estado -lo que dio lugar a un fuerte debate en las Cortes por lo que suponía de reducción de los derechos y garantías para las arcas públicas-, y tener la posibilidad de emitir obligaciones para atender las necesidades del astillero ${ }^{26}$. El Consejo de Administración quedó compuesto por José Martínez Rivas como Presidente, su cuñado Juan Amann Palme como Secretario, y como vocales su hermano Francisco, su yerno Adolfo Gabriel Urquijo Ybarra y Charles M. Palmer, que no vio de buen grado la operación. Los problemas financieros se acrecentaron y surgieron nuevas diferencias con el socio británico en lo concerniente al desembolso del capital y al despido del director gerente, John P. Wilson, pero, a pesar de ello, los otros dos cruceros, el Vizcaya y el Almirante Oquendo, fueron botados el 8 de julio y el 3 de noviembre de 1891, respectivamente. Rivas buscó financiación a través de una emisión de obligaciones, pero fracasó con estrépito, y se entrevistó con Cánovas para obtener algún adelanto sobre los plazos previstos, a lo que se negó el dirigente conservador; éste, no obstante, hizo gestiones para interesar a algún nuevo socio capitalista, aunque sin éxito ${ }^{27}$. En abril de 1892, Rivas anunció la imposibilidad de continuar con los trabajos y solicitó la intervención puntual del Gobierno con el fin de terminar los buques, pero éste, para garantizar con mayor firmeza la finalización de las obras y la defensa de sus derechos, decidió en mayo rescindir el contrato con el empresario e incautarse de la factoría ${ }^{28}$. Los motivos del fracaso de Martínez Rivas fueron muy debatidos en la prensa y también en las Cortes. El empresario acusó a Palmer de no haber cumplido con sus compromisos financieros y a Cánovas de no haberle apoyado, pero en realidad la más que probable causa fundamental de la quiebra del astillero estribó en la ambición del empresario por hacer una factoría desmedida, incluyendo en ella instalaciones para la producción de acero y laminados y un taller de forja para la fabricación de cañones, esperando posiblemente la obtención de nuevos pedidos del Estado. El proyecto que Rivas trató de llevar adelante sin el capital necesario excedió en dimensiones y en costes la demanda de construcciones navales que debía absorber. No en vano su antiguo director gerente, Clapham,

\footnotetext{
${ }^{26}$ Para una explicación de las causas que llevaron a la transformación de la sociedad colectiva en anónima véanse Arana (1985) y Marcos Viñas (1988).

27 Según Arana (1985, p. 1300), ese nuevo socio capitalista que buscó Cánovas fue Víctor Chávarri, quien rechazó la propuesta alegando que no deseaba asociarse en empresa alguna con Martínez Rivas.

${ }^{28}$ Ybarra Bergé (1947, pp. 144-146); Rodríguez (1988, pp. 279-281); Valdaliso (1991, pp. 289-291).
} 
diría en 1896 que «había[n] montado [su] factoría a la altura de las primeras del mundo para realizar en ella todo género de construcciones navales» ${ }^{29}$. El empeoramiento de las expectativas del negocio y el aumento de las necesidades alertaron a Palmer y a cualquier otro posible socio capitalista, y el incremento de los costes previstos, a pesar de la protección, alejó a la demanda privada ${ }^{30}$.

A partir de mayo de 1892, las construcciones siguieron adelante bajo la dirección de una comisión de la Marina encabezada por el entonces capitán de fragata Pascual Cervera Topete, asistido por Benito de Alzola en calidad de director técnico. Los problemas inmediatos más graves a los que hubo de enfrentarse fueron la alarma de los proveedores británicos y la intención del personal obrero y técnico inglés de abandonar la factoría y retornar a su país. En la solución de ambos desempeñó un papel fundamental el ya ex-socio de Martínez Rivas, Palmer, que en junio aceptó mantener una labor de asesoramiento cerca de la nueva dirección del astillero a cambio del cobro de 150.000 pesetas. En realidad, sólo se acercó a Bilbao en un viaje de dos días que efectuó en agosto y ya no volvió a visitar la factoría. Su verdadera tarea consistió en convencer a sus paisanos, tanto a los proveedores como a los obreros y técnicos, de que el Gobierno español garantizaría las deudas y los salarios pendientes de cobro, como así fue, y de esta manera tanto unos como otros continuaron prestando sus servicios de provisión de materiales y de trabajo y conocimientos técnicos para la terminación de los cruceros $^{31}$. Lo cierto es que Palmer, una vez se hubo acentuado su enfrentamiento con Rivas debido a las sucesivas disputas relacionadas con el taller de forja, la constitución de la sociedad anónima, los problemas financieros y el despido de Wilson, decidió alejarse del negocio y consideró las 150.000 pesetas como una indemnización por los perjuicios ocasionados ${ }^{32}$.

Mientras la construcción de los buques reanudaba su curso, las relaciones del Estado con el grupo de Martínez Rivas se tornaron difíciles, pues los dueños del astillero consideraron en un principio que la incautación había sido ilegal y entablaron una demanda judicial. Cambiaron de actitud de forma paulatina y suavizaron sus

${ }^{29}$ AGM, Astilleros del Nervión, leg. 4.275.

${ }^{30}$ Ybarra Bergé (1947, pp. 184-186); Arana (1985, p. 1299); Rodríguez (1988, pp. 276280); Valdaliso (1991, pp. 121-122 y 289-291). Para la protección a la industria naval, véase Berdún (2002).

${ }^{31}$ Entre los 2.878 trabajadores con que contaba la plantilla antes de la incautación se encontraban 180 británicos, y una proporción similar se mantuvo tras la intervención de la Marina: 122 -más 3 de otras nacionalidades- de un total de 1.787 operarios a la altura del 1 de junio de 1893. De ellos, 98 estaban ocupados en el taller de maquinaria, 26 en el astillero y sólo uno en armamento. AGM, Astilleros del Nervión, legs. 4.232 y 4.235.

32 AGM, Astilleros del Nervión, leg. 4.226. Por otra parte, la Marina estableció comisiones delegadas en Londres y París para comprar todo el material necesario una vez recuperada la confianza de los proveedores. Motores, blindaje, cañones y bronces fueron adquiridos en el extranjero. AGM, Astilleros del Nervión, leg. 3.528. 
reclamaciones al tiempo que las construcciones tocaban a su fin -en realidad, sólo el primero de los tres buques se terminó en las gradas bilbaínas-, de tal manera que, a la altura de 1896, se entablaron negociaciones formales para la devolución de los astilleros incautados ${ }^{33}$. Martínez Rivas, su yerno Adolfo Urquijo y el director gerente, William Clapham, protagonizaron las conversaciones con los representantes del Gobierno $^{34}$. Según un escrito firmado por Clapham, la incautación les había provocado unos daños irreparables por diversos conceptos -entre los que incluían la pérdida de contratos, la degradación de la maquinaria y la imposibilidad de presentarse a concursos- que elevaba la deuda del Estado a 58,9 millones de pesetas, cifra que fue calificada de absurda y rechazada tajantemente por los responsables de Marina. Una nueva liquidación practicada por éstos dio el resultado contrario de que el grupo de Rivas debía al Estado algo más de 14 millones debido al exceso del coste de los buques sobre lo pactado en 1889. Finalmente, nuevas negociaciones permitieron que en 1900 el empresario recuperara los Astilleros del Nervión a cambio de devolver a la Hacienda Pública 10 millones de pesetas en el plazo de nueve años, hipotecando la factoría como garantía del cumplimiento de esta obligación ${ }^{35}$.

\section{LA MARCHA DE LAS EMPRESAS}

La muerte del segundo marqués de Mudela en 1890 fue un acontecimiento determinante en la vida económica de José Martínez Rivas, porque le convirtió en propietario de los intereses siderúrgicos y navieros que hasta entonces había administrado -y del terreno en que se asentaban los Astilleros del Nervión-, una vez hubo pactado con sus hermanos la conversión de sus derechos en cuentas a interés fijo anual. Así, en la primera mitad de la década de 1890 quedó configurado definitivamente su entramado de negocios, que se resume en el cuadro siguiente. Se hace difícil valorar su riqueza entonces y más aún relacionarla con la de otros potentados de su época, porque sólo después de su muerte en 1913 se tasó su fortuna (en casi 16 millones de pesetas). Pero algo puede decirse atendiendo al tamaño de sus negocios. Rivas fue considerado en la década final del siglo XIX como uno de los industriales más acaudalados de Vizcaya, similar en cuanto a riqueza y poder social a personajes como Víctor Chávarri Salazar y Tomás Zubiría

\footnotetext{
${ }^{33}$ Rodríguez (1988, p. 281). Cuando se cerró la factoría en 1895 quedaban en nómina 700 operarios. Fusi (1975, pp. 139-150).

${ }^{34}$ Edmund William Clapham se convirtió en nuevo director gerente -más nominal que efectivo- de la sociedad Astilleros del Nervión y en uno de los máximos hombres de confianza de Rivas a partir de que dimitiera el que lo había sido hasta la incautación, James S. Clark, que a su vez había sustituido a John P. Wilson en diciembre de 1891. AGM, Astilleros del Nervión, leg. 4.225.

${ }^{35}$ AGM, Astilleros del Nervión, legs. 4.275 y 4.276; Ybarra Bergé (1947, pp. 184-188 y 201204); Allende (1993, pp. 60-61).
} 
Ybarra. Encabezaba junto a ellos y a otros pocos nombres los sectores de la minería del hierro y la siderurgia y, aunque no tan destacados, también eran considerables sus intereses en el sector naviero y en la minería del carbón asturiano. Antes de producirse la incautación, sus Astilleros del Nervión le otorgaban un incuestionable primer puesto en el sector de la construcción naval. Si dentro del paisaje empresarial español de la década de 1890 hubiera que escoger algún nombre vizcaíno, Chávarri, Zubiría y Martínez Rivas habrían sido los tres evidentes candidatos.

\section{CUADRO 2}

ENTRAMADO EMPRESARIAL DE JOSÉ MARTÍNEZ RIVAS (1872-1894)

\begin{tabular}{|c|c|c|}
\hline Minería del hierro & Navieras & Siderurgia \\
\hline 1872: & 1876: & 1879: \\
\hline Minas Unión y Amistosa & Vapores Fay y Somorrostro & Director de San Francisco del \\
\hline (en asociación con la & 1891: & Desierto \\
\hline Somorrostro Iron Ore) & C. del Vapor Mudela & 1886-1891: \\
\hline & C. del Vapor Marqués de Mudela & Dueño de San Francisco del \\
\hline Otras explotaciones menores & C. del Vapor Rivas & Desierto \\
\hline Construcción naval & Carbón & Inmuebles \\
\hline 1889: & 1894: & Fechas indeterminadas: \\
\hline Martínez Rivas, Palmer y & Coto del Musel & Adquisiciones diversas \\
\hline Compañía & & 1894: \\
\hline 1891: & & Finca de La Galea \\
\hline Astilleros del Nervión & & (157 hectáreas) \\
\hline
\end{tabular}

Fuente: Ver texto.

Según este esquema, Rivas habría desarrollado una clara estrategia de integración vertical de sus empresas, de forma que la demanda de una fuera cubierta por la oferta de otra. No cabe duda de que esto fue así en parte y de que esa estrategia desempeñó su papel en las decisiones del empresario, pero una mirada más detenida a cada uno de los negocios y a sus relaciones con el resto obliga a matizar dicha impresión. En primer lugar, la personalidad naviera de Rivas nunca fue lo suficientemente relevante como para cubrir las necesidades de tráfico de la producción de 
mineral y lingote, lo cual habría constituido su objetivo inicial. En segundo, la fábrica de San Francisco aprovechó el input que ofrecían las minas Unión y Amistosa en una parte muy pequeña, ya que el principal destino del mineral siguió siendo la exportación, y algo parecido puede decirse del carbón asturiano, cuya producción era superior a las necesidades de la empresa siderúrgica. En tercero, los Astilleros del Nervión emplearon laminados de otras empresas siguiendo la misma lógica de atender a su propia conveniencia en costes, manteniéndose la fábrica de San Francisco exclusivamente como productora de lingote hasta $1904^{36}$. Y, por otra parte, jamás obtuvieron un pedido procedente de las necesidades de su dueño en el sector naviero, que adquirió sus buques en el extranjero debido a su menor precio.

Así, cada negocio tuvo vida propia independiente de los demás, y a cada uno de ellos le fueron las cosas de manera diferente. Dispongo de poca información acerca de los beneficios de cada una de sus empresas, pero puedo esbozar un cuadro general a partir de lo que he podido calcular para la minería y de las informaciones que poseo sobre el resto de sectores. Lo primero que hay que decir es que la adquisición de las minas Unión y Amistosa a principios de la década de 1870 fue un negocio fabuloso para Martínez Rivas. No requirió además de grandes inversiones posteriores si se exceptúan los tres tranvías construidos en 1872, 1874 y 1893, que enlazaban las explotaciones con el Ferrocarril de Triano - de la Diputación de Vizcaya-, por el cual se transportaba el mineral hasta los embarcaderos del Nervión a precios inferiores a los de otros ferrocarriles privados ${ }^{37}$. Rivas se convirtió ya en la década de 1880 en uno de los empresarios mineros más potentes de Vizcaya, situándose en algunos años sólo por detrás de la Orconera Iron Ore, con producciones que llegaron a sobrepasar las 800.000 toneladas anuales en la década de 1890 para luego ir descendiendo de manera paulatina.

Rivas extrajo entre 1880 y 1913 una media de 501.000 toneladas anuales, lo que representó el 11,4\% del total de Vizcaya ${ }^{38}$. Siendo esto así, no sorprende que los beneficios fueran también abultados. Para estimarlos he empleado dos vías diferentes, cuyos resultados, sin embargo, se aproximan: en ese periodo, el empresario ganó entre 48,3 y 49,7 millones de pesetas de beneficios, lo que da una media de

\footnotetext{
${ }^{36}$ Debo esta información a Mikel Sáez García. Ya he indicado antes que la construcción de talleres de fabricación de acero y laminados en la factoría fue interrumpida antes de su finalización.

${ }^{37}$ En realidad, no es seguro si la construcción de los tranvías corrió a cargo de Martínez Rivas o de la Somorrostro Iron Ore, porque N. de la Puerta (1994, p. 209) los adscribe a la compañía británica basándose en el ingeniero Julio Lazúrtegui y otros, y Echevarría (1900) dice que son del empresario español. Sí parece cierto que el de 1872, que correspondía a la mina Amistosa, fue el primero que se levantó en la cuenca minera vizcaína. Cada uno de los tres poseía una capacidad de carga de $900 \mathrm{Tm}$. diarias y juntos tenían una longitud de 7,2 km. Sobre las tarifas de los ferrocarriles mineros véase Escudero (1998, pp. 204-205).

${ }^{38}$ Según cálculos propios a partir del BOPV. Para 1880, 1900 y 1913, y para las producciones totales anuales de Vizcaya, véase Escudero (1998, pp. 179 y 305).
} 
1,42-1,46 millones de pesetas al año ${ }^{39}$. El único dato de que dispongo a partir de la contabilidad dentro del periodo analizado es el de 1913, que coincide de manera llamativa con la estimación: 1.445 .460 ptas $^{40}$. A la vista de estas cifras, es seguro afirmar que la minería constituyó para Martínez Rivas una duradera fuente de rentas, y de hecho la contabilidad de 1913 consigna la práctica del empresario de descontar directamente de los beneficios de sus explotaciones mineras sus gastos corrientes y los de su familia, que, por ejemplo, en aquel año fueron de 382.600 pesetas $^{41}$. Esta costumbre solía practicarse con aquella empresa del entramado de negocios que fuera más fiable en cuanto a la obtención de beneficios y menos sujeta a oscilaciones no deseadas, como sabemos que hicieron otras casas empresariales ${ }^{42}$.

La fábrica de San Francisco, por su parte, se reconvirtió en 1894 en una sociedad anónima con un capital social de cinco millones de pesetas, dividido en 200 acciones de 25.000 pesetas cada una, propiedad de Martínez Rivas a excepción de cuatro de ellas, que se repartieron dos de los más asiduos colaboradores del empresario: su cuñado Blas Alzaga y William Clapham. Aunque cuento para analizar su evolución con todos los inventarios de la empresa efectuados entre ese año y 1913, muchos aspectos de la misma no pueden ser clarificados debido a las irregulares prácticas contables de su responsable máximo. Los resultados sólo fueron consignados expresamente algunos años, y la cifra del capital social permaneció invariable, al tiempo que una cuenta corriente a nombre de Rivas ascendía o descendía según que la

${ }^{39}$ Las dos vías de estimación han sido las siguientes. En primer lugar, según Escudero (1998, pp. 275-277), los grandes mineros vascos habrían obtenido de beneficios entre 1876 y 1897 una media de 3 pesetas por tonelada, y de 6,5 ptas entre 1898 y 1913. Siendo esto así, Rivas obtuvo unos beneficios de 27,4 y 35 millones respectivamente, o sea, 62,4 millones, fundamentalmente de la explotación de las minas Unión y Amistosa. Ahora bien, el 70\% de la mina Unión no era suyo, ya que se limitaba a cobrar una peseta por tonelada que vendiera para la Somorrostro Iron Ore de ese porcentaje. Según mis cálculos, que proceden del BOPV, la mina Unión produjo el 42,5\% del total que habitualmente se asignó a Rivas, lo que obliga a descontar los beneficios correspondientes a casi un 30\% de su producción $(0,425$ x 0,7 =0,2975), y añadir una peseta de canon por tonelada. El resultado es que Rivas obtuvo en total unos beneficios de 48,3 millones de pesetas. En segundo lugar, si hacemos el cálculo a partir de los beneficios generales anuales del sector propuestos por Escudero (1998, p. 343), nos queda lo siguiente: entre 1880 y 1913, el sector obtuvo 564,3 millones. Corresponde a Rivas un 11,4\%, esto es, 64,3 millones. Si hay que descontar un $30 \%$ por los motivos ya indicados se queda en 45,2 millones, a los que hay que sumar la peseta por Tm. correspondiente a la producción de la Somorrostro, con lo que sube a 49,7 millones de pesetas. Así pues, la diferencia entre ambas estimaciones es de 1,4 millones, que, divididos entre 34 años que tiene el periodo, se reduce a tan sólo 41.000 ptas. anuales. En todos los cálculos he supuesto que la mina Amistosa fue propiedad de Rivas al menos desde 1884, lo cual resulta lógicamente de lo que sé acerca de las otras explotaciones y del acuerdo para la explotación del $70 \%$ de Unión, que no menciona a Amistosa.

${ }^{40}$ AY, leg. 492, carta de Ángel Jausoro al Conde de Urquijo fechada el 6.8.1914. El resto de los datos con que cuento sobre beneficios corresponde al periodo 1914-1919, que no conviene comparar con otros años sin tener en cuenta sus especiales circunstancias.

${ }^{41}$ AY, leg. 492, carta de Ángel Jausoro al Conde de Urquijo fechada el 6.8.1914.

${ }^{42}$ Echevarrieta, por ejemplo, lo hizo durante la década de 1920 con su fábrica de cemento Portland Yberia. Véase Díaz Morlán (1999, p.189). 
empresa obtuviera beneficios o pérdidas ${ }^{43}$. Cinco de las siete partes en que se había dividido la herencia se convirtieron en cuentas a nombre de la madre y los cuatro hermanos de José, mientras el empresario tasaba sus dos séptimos -su parte y otra que había adquirido al único heredero de otra rama familiar- y todos los pactos y derechos de la factoría en la cifra redonda de cinco millones de pesetas ${ }^{44}$. Además, las cuentas de sus familiares permanecieron estancadas, lo que sin duda quiere decir que los beneficios se fueron acumulando en su propia cuenta mientras pagaba un interés fijo a su madre y sus hermanos, a los que terminó por adquirir sus participaciones en los primeros años del siglo XX.

Como resultado de esta práctica contable, si en 1894 el capital era de cinco millones y el saldo de la cuenta de Rivas de 3.618 .388 pesetas, en 1908 se había pasado a un capital de 6.575 .000 pesetas y a una cuenta personal de 16.274 .178 pesetas. Rivas cobraba su interés sobre esta cuenta, y el sobrante de beneficios se añadía a ella sin alterar el capital nominal y sin crear reservas. Esta era la forma contable de articular la acumulación de capital producida por la fábrica de San Francisco. Sin embargo, no es posible conocer por esta fuente los beneficios de la empresa en todos los años, porque los incrementos de la cuenta de Rivas podían deberse a éstos o bien a aportaciones de su titular provenientes de sus otros negocios, singularmente los mineros. Para los ejercicios en que sí se mencionaron los resultados, de 1905 a 1908, en todos ellos se sufrieron pérdidas, que, sumadas, ascendieron a 2,8 millones de pesetas. Cabe pensar que la participación en la Central Siderúrgica a raíz del comienzo de la fabricación y laminación de acero en 1904-1905 -que sí puede certificarse por los inventarios- dio sus frutos a largo plazo, y, de hecho, las pérdidas de 1908 fueron sólo un tercio de las de 1907. En 1913 hubo beneficios, que ascendieron a la respetable cifra de 826.295 pesetas, pero las continuas menciones a la descapitalización de la factoría y la antigüedad de sus instalaciones en los años posteriores a la muerte de Rivas no invitan a pensar en una fuerte política de amortizaciones y reinversiones. Que ello se debiera a la cortedad de los beneficios o a una excesiva generosidad en su reparto es algo que por el momento escapa a mi conocimiento ${ }^{45}$.

\footnotetext{
${ }^{43}$ Dicho capital no varió hasta 1909, y cuando lo hizo en este año fue para corresponder a la incorporación al activo de las diversas propiedades inmobiliarias de Martínez Rivas, como la finca de la Galea y las casas de Las Arenas y Bilbao.

${ }^{44}$ En esos derechos incluyó, por ejemplo, el contrato de arrendamiento de terrenos para las instalaciones de Astilleros del Nervión, el convenio con la Diputación de Vizcaya, el derecho a adquirir las otras cinco séptimas partes, un convenio con un empresario metalúrgico y otro con una compañía de cementos. Pero la tasación que se hizo de todos estos derechos careció por completo de base real. AM, leg. 534/5 y AFV, AHV, leg. 1198.

${ }^{45}$ AFV, AHV, leg. 1198. Martínez Rivas envió a Blas Alzaga en marzo de 1904 para negociar con los representantes de la Central la participación de la San Francisco, después de la respuesta que dieron los asociados - en forma de rebaja de los precios- a su agresiva entrada en el mercado. Debo esta información a la amabilidad de Mikel Sáez García, que me facilitó los documentos en que se hace referencia a tales negociaciones.
} 
Por lo que respecta al Coto del Musel, a lo largo de todo el periodo mantuvo una gran estabilidad, ocupando el puesto diecisiete dentro de la relación de las grandes empresas del sector en España y alcanzando su producción 53.000 toneladas en 1900 y 52.000 en 1910. Aplicando a estas cifras los beneficios unitarios anuales calculados por Coll para una muestra de empresas carboníferas -obtenidos a partir de las memorias de las compañías- pueden estimarse los beneficios medios del Coto del Musel en 110.000 pesetas al año, lo que habría supuesto un 11\% sobre el capital social, inamovible en todos estos años de su cuantía inicial de un millón de pesetas. Es una cifra, no obstante, que debe tomarse sólo como una referencia indicativa del peso del negocio en el entramado empresarial de Martínez Rivas, considerablemente menor que el de la minería del hierro o la siderurgia. En cualquier caso se trató de una empresa rentable, como indican dos datos: el único cuantitativo que poseemos, el de los beneficios de 1913, que ascendieron a 400.000 pesetas -por encima de los ofrecidos por Coll para su muestra de empresas grandes no ferroviarias- y el cualitativo de que los herederos de Rivas se mostraron reacios a vender esta compañía no sólo durante los años extraordinarios de la guerra mundial, sino también después ${ }^{46}$.

Por su parte, el sector naviero estuvo caracterizado por una extrema irregularidad en el largo periodo que estamos considerando, con etapas de gran auge, como la de los últimos años del siglo XIX, entremezcladas con otras de crisis, como las de 1901-1904 y 1908-1910. Pero ni estas oscilaciones ni los cambios legislativos como la Ley de Comunicaciones Marítimas de 1909-que otorgaba primas a los buques de bandera nacional, entre otras medidas de apoyo al sector-, definieron la estrategia naviera de Martínez Rivas de la misma manera en que lo hicieron a propósito de otras casas empresariales ${ }^{47}$. A partir de la constitución de las tres compañías de un solo barco, en 1891, se dedicó a gestionarlas sin incrementar su flota, ni siquiera en los favorables años finiseculares, y esos mismos buques envejecidos se encontraron en 1913 sus herederos, que los venderían a buen precio durante la coyuntura bélica. Esta forma de actuar tan conservadora después de un inicio tan precoz y prometedor contrasta con la estrategia expansiva posterior de otros navieros bilbaínos, como Sota, Aznar o Echevarrieta, pero coincide con lo que puede observarse para el resto de sus negocios. En efecto, las tempranas realizaciones en la minería, la siderurgia, el carbón y la actividad naviera colocaron a Rivas en uno de los primeros puestos del mundo empresarial vizcaíno. Pero la fábrica de San Francisco no siguió el ritmo expansivo de sus competidoras, cuyo máximo exponente fue la creación de Altos Hornos de Vizcaya en 1901; el Coto del Musel no pasó nunca del puesto diecisiete entre las grandes del sector carbonífero mientras las sociedades

\footnotetext{
${ }^{46}$ AY, leg. 492, carta de Ángel Jausoro al Conde de Urquijo fechada el 6.8.1914; Coll y Sudrià (1987, pp. 220-222 y 254-255).

${ }^{47}$ Valdaliso (1991, pp. 123-127); Díaz Morlán (1999, pp. 88-95).
} 
relacionadas con Ybarra, Chávarri y otros crecían, y el número de barcos de su propiedad permaneció estancado al tiempo que se creaban las grandes compañías marítimas con matrícula de Bilbao. En el apartado siguiente trataré de dar una interpretación a esta llamativa apatía empresarial ${ }^{48}$.

Por último, los Astilleros del Nervión se reabrieron en 1902 coincidiendo casi en el tiempo con la creación por Ramón de la Sota y Eduardo Aznar de la Compañía Euskalduna de Construcción y Reparación de Buques, que data de 1900. Pero a diferencia de Sota y Aznar, dueños principales de una de las mayores flotas mercantes del país, la Casa Martínez Rivas, como ha quedado dicho, no tuvo una personalidad naviera destacada y la factoría no recibió encargos importantes de nuevas construcciones y reparaciones provenientes del sector privado, habiendo de conformarse con pequeñas embarcaciones como pesqueros, gabarras, ganguiles y balandros para regatas. En total se llevaron a cabo 60 construcciones, de las que 32 fueron balandros, 8 de ellos para la familia real ${ }^{49}$. Astilleros del Nervión no hizo ningún barco de gran tonelaje hasta 1915, cuando la coyuntura bélica multiplicó los precios de los mercantes. Este hecho lastró la marcha de la factoría y contrarió de nuevo las expectativas de su dueño ${ }^{50}$. S. Houpt y J. C. Rojo han ofrecido la cifra de 11 millones de pesetas de pérdidas acumuladas entre 1902 y 1912 y, aunque no citan la fuente, el dato es plausible si se añade la descapitalización de la factoría a las pérdidas reflejadas en la contabilidad, que ascendieron a 1.218 .700 pesetas $^{51}$. De

\footnotetext{
${ }^{48}$ Puede obtenerse una imagen de la decadencia empresarial de la Casa Martínez Rivas en el informe que la dirección de Altos Hornos de Vizcaya redactó en 1919 con la mirada puesta en su posible adquisición. Se decía en dicho informe que todos los elementos de trabajo de la fábrica San Francisco y Astilleros del Nervión se encontraban «completamente anticuados» y que la primera determinación en caso de que se produjera la compra «tendría por objeto derribar todas las instalaciones adquiridas para dejar la superficie completamente libre». AA, leg. 16, «Informe de la administración sobre la adquisición de la propiedad de Martínez Rivas enclavada en el Concejo de Sestao», pág. 3.

${ }^{49}$ Guiard (1968, pp. 274-275); Ossa (1969, pp. 158, 245-246); Rodríguez (1988, p. 279). Sin duda, en la especialización de Astilleros del Nervión en la construcción de pesqueros, gabarras y ganguiles debió de influir la Ley de Fomento a las Industrias y Comunicaciones Marítimas aprobada en 1909, que reservaba para buques nacionales la navegación de cabotaje, los servicios de puerto y la pesca marítima. Véase Berdún (2002, p. 169).

${ }^{50}$ La falta de una flota mercante que respaldara la actividad de los astilleros fue también la causa de los problemas que tuvo otro empresario, Horacio Echevarrieta, en las décadas de 1920 y 1930, a diferencia de las mayores ventajas que disfrutaron la Compañía Euskalduna de Sota y Aznar, la Sociedad Española de Construcción Naval por su unión a la Transatlántica del grupo Comillas, y la Unión Naval del Levante por su relación con la Transmediterránea de Juan March. El paralelismo es llamativo, y más si se tiene en cuenta que Echevarrieta intentó comprar a los herederos de Martínez Rivas los Astilleros del Nervión en 1916, sin caer en la cuenta de la importancia de esa falta de integración vertical.

${ }^{51}$ Houpt y Rojo (1998, pp. 66-67); pérdidas contables, en AY, 492, 495 y 505, cartas de Ángel Jausoro al Conde de Urquijo fechadas los días 6.8.1914, 17.3.1915, 28.3.1916, 20.3.1918 y 5.4.1919.
} 
hecho, entre 1917 y 1918 fueron empleados 9 millones de pesetas de los beneficios extraordinarios obtenidos gracias a las circunstancias de la guerra mundial en sanear las cuentas de los Astilleros del Nervión y en amortizar sus viejas instalaciones $^{52}$. En 1913, año de la muerte de José Martínez Rivas, la empresa logró unos beneficios de 270.000 pesetas, pero aunque a primera vista pareció que los herederos recibían un negocio problemático y descapitalizado, en realidad lo que obtuvieron fue un punto de partida privilegiado para aprovechar la imprevista coyuntura bélica que estaba a punto de llegar.

\section{ANÁLISIS SCHUMPETERIANO DE LAFUNCIÓN EMPRESARIAL}

Como es sabido, J. A. Schumpeter dejó establecida en su obra de 1912, Teoría del desarrollo económico, una definición de la función empresarial, según la cual corresponde al empresario la tarea fundamental de introducir nuevas combinaciones en la economía que destruyan el equilibrio antiguo y tiendan hacia uno nuevo. Esta labor de destrucción creadora, según el economista austríaco, es la definitoria de la función empresarial. El concepto de empresario, en este contexto teórico schumpeteriano, es sinónimo de innovador o de introductor de nuevas combinaciones, y excluye otras funciones como las de dirección del negocio o la asunción del riesgo. El éxito en la introducción de una nueva combinación se transforma en beneficio empresarial puro, distinto del sueldo de gerencia o del interés del capital, que va a parar al empresario como premio por desarrollar su función. Para llevarla a cabo, el empresario contrata a los demás factores de producción y para ello debe recurrir, cuando así es necesario por no poseer medios de fortuna propios, a la adquisición de capacidad de compra-capital, en el sentido definido por Schumpeter- a cambio de un interés, que es el pago que recibe el capitalista por adelantar al empresario dicha capacidad de compra con la que llevar adelante su nueva combinación ${ }^{53}$.

Veremos a continuación hasta qué punto y con qué posibles matices la idea que Schumpeter tenía de la función empresarial puede servir para entender la actividad de José Martínez Rivas. En el primero de sus negocios, la adquisición de las minas Unión y Amistosa, actuó como un verdadero empresario schumpeteriano,

${ }^{52}$ AY, leg. 505, cartas de Ángel Jausoro al Conde de Urquijo fechadas los días 20.3.1918 y 5.4.1919.

${ }^{53}$ Para la concepción que Schumpeter tuvo del papel desempeñado por el capital y los bancos en su relación con el proceso de desarrollo económico a través de la creación del crédito, véase Messori (1983) y (1984); Morishima y Catephores (1988), y Arena y Festré (1996). Síntesis generales del pensamiento de Schumpeter pueden encontrarse en Clemence y Doody (1950), Perroux (1965), Wol (1982), Hébert y Link (1982), Heertje (1988), y Vence (1995). 
consiguiendo la capacidad de compra necesaria para llevar a la práctica su idea sin contar con medios propios de fortuna en un primer momento, aunque no a cambio de un interés concedido al capitalista por su aportación, como en el esquema establecido por el economista austriaco, sino mediante la cesión de una parte de su negocio, en este caso traducida en el 70\% de la mina Unión y, al menos al principio, la totalidad de Amistosa. Es decir, haciendo a la empresa Somorrostro Iron Ore, que en este caso actuó como capitalista, partícipe mayoritaria de los beneficios esperados de la nueva combinación -según la terminología de Schumpeter- puesta en marcha por el empresario. De esta forma, parece que debe introducirse aquí un matiz que no carece de importancia dentro del esquema schumpeteriano. La clave del problema puede hallarse en que la ganancia empresarial pura de la que hablara Schumpeter tiene carácter comercializable. El titular de la función empresarial -el empresariopuede vender su capacidad de ganancia, y de hecho puede necesitar hacerlo para obtener los otros factores de producción que necesita para llevar a cabo la nueva combinación. Por regla general, lo que hará será vender su capacidad de ganancia para adquirir capacidad de compra. Esto supera el fenómeno del interés según lo percibió Schumpeter porque, en caso de éxito de la nueva combinación, el empresario percibirá lo pactado con el capitalista, y el capitalista se quedará con la ganancia o parte de ella. En el caso que nos ocupa, Martínez Rivas se vio obligado a enajenar el 70\% de los posibles beneficios que deparase la mina Unión y la totalidad de los de Amistosa -al menos al principio- a cambio de poder llevar a cabo su nueva combinación en la minería vizcaína, teniendo que conformarse con la esperanza de una parte minoritaria del futuro beneficio. En el caso de los buques, la hipoteca naval no implicó una participación en la propiedad de quien prestó el capital, que se conformó con la percepción de un interés, pero Rivas necesitó hacer partícipes del negocio a su tío y a su primo, a los que correspondió una parte mayoritaria de la propiedad de los buques $^{54}$. De nuevo, el empresario recurrió a la obtención de soporte financiero -en este caso, y típicamente, de su familia- a cambio de entregar buena parte de las futuras ganancias, hasta que él, su madre y sus hermanos heredaron los barcos en 1890 y pudo hacerse por fin con el control absoluto de su propiedad.

En la adquisición de la fábrica de San Francisco se encuentra de nuevo un ejemplo de función empresarial al estilo de la definida por Schumpeter, aunque en esta ocasión mezclada con la de capitalista, ya que José contaba con medios propios de fortuna cuando entre 1886 y 1890 se convirtió en propietario de la factoría siderúrgica. El éxito de sus negocios anteriores le permitía ya disponer de suficiente

${ }^{54}$ No obstante, véase, entre otros trabajos del mismo autor, Valdaliso (1996, pp. 306 ss.), en donde se indica que, en la mayoría de las ocasiones, el empleo de la hipoteca naval no alejaba a los prestamistas británicos de la explotación del buque. El caso de Martínez Rivas habría constituido, por consiguiente, una excepción dentro de ese panorama. 
capacidad de compra sin tener necesidad de pedírsela a otros capitalistas a cambio de un interés o mediante la cesión de parte de su nuevo negocio. Esto es, se había convertido él mismo en capitalista, aunque con una salvedad importante. Los derechos que sobre la fábrica recayeron sobre su madre y sus hermanos los adquirió a cambio de abrir a cada uno de ellos una cuenta con interés contra la fábrica, lo que supuso sencillamente otra forma de pedir prestada una parte del capital necesario para la nueva combinación -de nuevo a la familia-, satisfaciendo así las condiciones que estableció Schumpeter para su definición de empresario en su concepción más pura.

Los Astilleros del Nervión, por su parte, constituyeron un verdadero salto schumpeteriano que sin embargo se saldó con un indudable fracaso, el cual lastró sus finanzas e influyó de manera determinante en su actividad económica. Esto no tiene nada de extraño, pues el hecho cierto del fracaso empresarial ya fue recogido por el mismo Schumpeter, que lo utilizó para explicar la cuantía de los beneficios del innovador exitoso. Su carácter en ocasiones tan elevado, si provocaba las críticas de la opinión pública era porque ésta no tenía en cuenta las ocasiones en que los fracasos llevaban a sufrir cuantiosas pérdidas. Schumpeter argumentó que si se sumaran hipotéticamente beneficios y pérdidas, el resultado neto no sería tan abultado. Sin necesidad de entrar en si puede o no justificarse de esta manera el tamaño de los beneficios empresariales, cabe indicar aquí que las pérdidas del fracaso del astillero sí redujeron considerablemente las ganancias que Martínez Rivas obtuvo con sus otros negocios, aunque en una cuantía prácticamente imposible de determinar con exactitud. Al coste sufrido durante su corto periodo de actividad inicial, entre 1889 y 1892, deben añadirse los 10 millones de indemnización pactada con el Estado para su devolución en 1900 -que pudieron haber sido bastantes más-, y las pérdidas habidas hasta 1912, cifradas en 1,2 millones, más como mínimo 9 millones en su descapitalización -esto es, la falta de una política de amortizaciones adecuada al envejecimiento de las instalaciones.

Pero tanto los astilleros como la mayor parte de sus otras iniciativas pueden englobarse en un mismo denominador común. Casi todas ellas, mal que bien, cumplen la otra condición introducida por Schumpeter para poder hablar de función empresarial, la de que se tratara de nuevas combinaciones destinadas a destruir las formas antiguas de hacer las cosas, rompiendo anteriores equilibrios para llevar a la economía hacia otros más elevados en producción e inferiores en costes. En el caso de las minas Unión y Amistosa no existen demasiadas dudas de que la fecha en que Rivas procedió a explotar a gran escala el criadero vizcaíno, el año de 1872, le sitúa por delante de cualquier otro empresario, quizá con la excepción de los Ybarra ${ }^{55}$.

${ }^{55}$ Los Ybarra y otros llevaban décadas comerciando con el mineral, pero fue en los primeros años de la década de 1870, coincidiendo con Rivas, cuando pactaron con compañías siderúrgicas extranjeras la explotación a gran escala del criadero. 
A su vez, parece que fue él el primero que construyó, en ese mismo año, un tranvía aéreo para unir sus explotaciones con el Ferrocarril de Triano, al que siguieron otros dos en 1874 y 1893. En el caso de la fábrica de San Francisco se le debe otorgar una incuestionable prioridad, pues se adelantó diez años a la constitución de las otras dos factorías siderúrgicas que establecieron métodos modernos de producción de lingote y acero. Rivas no fabricó acero hasta 1904, pero fue innovador en la apertura de nuevos mercados - una de las cinco formas de nueva combinación schumpeteriana- al levantar la fábrica con el objetivo de exportar lingote al extranjero. Y también fue temprana su entrada en el negocio naviero, en 1876, si bien en esta ocasión siguió los pasos de unos pocos empresarios que para entonces ya llevaban tiempo introducidos en dicho negocio.

Por lo que respecta a Astilleros del Nervión, no cabe duda de que se trató del primer intento de transformar en la economía de Vizcaya los métodos de la construcción naval, hasta entonces caracterizada por factorías pequeñas como las de Arana, Mendiguren o Cortadi, incapaces de albergar la construcción de buques de grandes dimensiones. Precisamente ese carácter prematuro y desmedidamente ambicioso de la innovación introducida por Martínez Rivas estuvo en el origen del error de apreciación que le llevó fatalmente al fracaso, al pensar que podría cumplir las condiciones del contrato con el Estado y hacerse al mismo tiempo con futuros pedidos de la Armada y con parte de la demanda civil. En este caso hay que añadir que la reducción en costes pudo existir si éstos se comparan con los que tenían los modestos astilleros antiguos, pero no fue suficiente para que la nueva factoría se mostrase competitiva frente a la competencia extranjera. Por último, el Coto del Musel no fue una nueva combinación en el sentido empleado para las anteriores iniciativas porque su fecha de constitución, el año de 1894, resulta algo tardía con respecto a la de aquellas otras casas empresariales españolas introducidas en el sector del carbón asturiano -el Marqués de Comillas, por ejemplo, lo hizo en la década de 1880, y en 1892 constituyó la Sociedad Hullera Española-, pero sí se puede afirmar que Martínez Rivas formó parte del reducido grupo de hombres de negocios vizcaínos que en aquel mismo tiempo integraron la hulla asturiana, palentina y leonesa en sus entramados de negocios ${ }^{56}$.

A partir de entonces, y manteniendo el punto de vista schumpeteriano, la función empresarial de Rivas habría terminado para dar paso a una meramente directiva y capitalista, disfrutando de los beneficios producidos por las nuevas combinaciones

${ }^{56}$ En concreto, parece que se anticiparon a Rivas sus dos competidores en la siderurgia: el grupo formado en torno a la figura de Víctor Chávarri y la fábrica de la Vizcaya constituyeron Hulleras del Turón en 1891, el mismo año en que el grupo de los Ybarra-Zubiría y Altos Hornos de Bilbao entraron en el capital de la Unión Hullera y Metalúrgica de Asturias. En 1893, este último grupo constituyó la Hullera Vasco-Leonesa. Vid. Coll y Sudrià (1987, pp. 202-207) y Valdaliso (1988). 
exitosas puestas en marcha entre 1872 y 1894, aunque disminuidos por las pérdidas derivadas del fracaso del astillero. Desde los últimos años del siglo XIX, Martínez Rivas no llevó a cabo ninguna otra iniciativa empresarial semejante a las descritas, salvo la de producción de acero y laminados en la fábrica de San Francisco en 1904 y la de poner de nuevo en marcha los Astilleros del Nervión tras recuperarlos en 1900, sin aportar siquiera soluciones financieras a la progresiva descapitalización de la factoría de construcción naval. En cierto sentido, esta relajación de su ímpetu en los negocios surgió de forma paralela a su separación de la política activa, tras haber protagonizado buena parte de las luchas electorales habidas en Vizcaya durante las dos primeras décadas de la Restauración. La personalidad innovadora de José Martínez Rivas se apagó más de una década y media antes de su muerte, ocurrida en 1913, y su nombre sólo volvió a destacar en ocasiones puntuales y más relacionadas con su peculiar posicionamiento en las huelgas mineras de 1910 y 1911 que con actuaciones de carácter netamente empresarial ${ }^{57}$.

\section{CONCLUSIONES}

La función empresarial schumpeteriana sirve bien al propósito de explicar la actividad del industrial José Martínez Rivas. Puede dividirse ésta en dos etapas. La primera arranca en 1872 y termina hacia 1894, y en ella se llevan a cabo todas las nuevas combinaciones. Es la época en que Rivas habría ejercido una función empresarial con prácticamente las mismas características que las definidas por Schumpeter. La segunda comienza a partir de la última fecha y llega hasta su muerte, en 1913. Son casi dos décadas de madurez capitalista, pero de falta casi absoluta de iniciativa empresarial. En la primera etapa, Rivas asciende en la escala social gracias al éxito de sus innovaciones y se convierte en uno de los capitalistas más relevantes de su época. Parte de una posición de privilegio porque logra introducirse en el mundo de los grandes negocios a través de su tío, el opulento Marqués de Mudela, quien financia en parte algunas de sus iniciativas. En otras ocasiones, Rivas obtiene el capital por otros medios, en líneas generales coincidentes con los descritos por Schumpeter. Así, sus primeros negocios mineros y navieros se efectúan a crédito, la fábrica siderúrgica no le pertenece en los primeros años y, para cuando se interna en la construcción naval y el carbón asturiano, es ya un capitalista que posee medios propios de fortuna. Dentro de este esquema general conviene, no obstante, introducir el siguiente matiz. En varias ocasiones, singularmente en la

${ }^{57}$ Esta desaparición de la función empresarial schumpeteriana en la actividad de quienes han sido grandes introductores de nuevas combinaciones ha sido estudiada para otros casos de empresarios innovadores, y algunos investigadores han planteado incluso la existencia de una pauta común para explicar dicho comportamiento. Véase Ronstadt (1986). 
primera, concerniente a la minería vizcaína, Rivas obtiene el capital necesario para llevar a cabo la nueva combinación a costa de sacrificar una parte mayoritaria del negocio y de sus futuros beneficios, que cede al capitalista -en este caso, la empresa Somorrostro Iron Ore. Otro tanto ocurre en la siderurgia y en la actividad naviera con respecto a su tío y a su primo. Las posibles derivaciones prácticas y teóricas que este matiz pueda tener, así como su capacidad explicativa para otros casos, no caben en el presente trabajo, por lo que me limito aquí simplemente a apuntarlas.

En la segunda etapa, Martínez Rivas recoge la cosecha de sus innovaciones anteriores de forma típicamente schumpeteriana. Abre de nuevo los Astilleros del Nervión y construye trenes de laminación, pero no lleva a cabo ninguna otra iniciativa digna de ser mencionada. Percibe en forma de rentas los beneficios derivados de sus nuevas combinaciones -parcialmente disminuidos por las pérdidas ocasionadas por su fracaso en la construcción naval- y llega al final de su vida con un entramado empresarial envejecido, que en buena parte se ha quedado atrás con respecto a las novedades que han ido surgiendo en varios de los sectores en los que está presente, con respecto a las cuales se mantiene ajeno. A la manera que también describió Schumpeter, este comportamiento no empresarial sino meramente gestor y capitalista debería haber empujado a Martínez Rivas hacia un destino marcado por la decadencia económica y social. Tal parecía ser el que esperaba a su entramado de negocios en 1913, cuando la extraordinaria coyuntura de la guerra mundial supuso para sus herederos una oportunidad inesperada de rehacer sus cuentas.

\section{FUENTES}

AA: Archivo del Marqués de Arriluce

AFV, AHV: Archivo Foral de Vizcaya, Fondo Altos Hornos de Vizcaya

AGM: Archivo General de la Marina D. Álvaro de Bazán

AHEV: Archivo Histórico Eclesiástico de Vizcaya

AHPM: Archivo Histórico de Protocolos de Madrid

AHPV: Archivo Histórico de la Provincia de Vizcaya, Sección Protocolos Notariales

AM: Archivo de la Fundación Antonio Maura

AY: Archivo Foral de Vizcaya, Fondo Ybarra Hermanos

BOPV: Boletín Oficial de la Provincia de Vizcaya, 1880 - 1913

\section{BIBLIOGRAFÍA}

Arana Pérez, I. (1985): «Aproximación al fracaso de un ambicioso proyecto empresarial. Astilleros del Nervión», en Symbolae Ludovico Mitxelena. Septuagenario Oblatae. Vitoria, pp. 1291-1301.

Arena, R. y Festré, A. (1996): «Banks, Credit, and the Financial System in Schumpeter: an Interpretation», en L. S. Moss (ed.), Joseph A. Schumpeter, Historian of Economics. Londres y Nueva York: Routledge, pp. 167-77. 
Allende Portillo, F. (1993): «Los empresarios vizcaínos como grupo de presión: sus logros y fracasos (1886-1975)». Bilbao: Universidad de Deusto. Tesis Doctoral.

Bahamonde Magro, A. y Otero Carvajal, L. E. (1989): La sociedad madrileña durante la Restauración (1876-1931). Madrid: Comunidad de Madrid, Consejería de Cultura. Vol. I.

Berdún ChÉLIz, P. (2002): «La política de ayudas directas a la industria naval y la marina mercante en torno al cambio de siglo: 1876-1918». Transportes, Servicios y Telecomunicaciones 3-4, pp. 145-179.

Clemence, R. V. y Doody, F. S. (1950), The Schumpeterian System. Cambridge, MA.: Addison Wesley.

Coll, S. y SUDRIÀ, C. (1987): El carbón en España, 1770-1961: una historia económica. Madrid: Turner.

Conde DE URquiJo (Adolfo Gabriel Urquijo Ybarra) (1918): Noticias genealógicas. Bilbao.

DíAz Morlán, P. (1999): Horacio Echevarrieta, 1870-1963. El capitalista republicano. Madrid: LID.

- (2002): Los Ybarra. Una dinastía de empresarios (1801-2001). Madrid: Marcial Pons.

ECHEVARRíA, I. (1900): Las minas de hierro en la provincia de Vizcaya. Bilbao.

Escudero, A. (1998): Minería e Industrialización de Vizcaya, 1876-1935. Barcelona: Crítica.

FeRnÁNDEZ DE PINEDo, E. (1987): «La industria siderúrgica, la minería y la flota vizcaína a fines del siglo XIX. Unas puntualizaciones», en VV.AA., Mineros, sindicalismo y política. Oviedo: Fundación José Barreiro, pp. 149-168.

- (1988): «Factores técnicos y económicos de la moderna siderurgia y la flota vizcaína, 1880-1899», en E. Fernández de Pinedo y J. L. Hernández Marco (eds.), La industrialización del norte de España. Barcelona: Crítica, pp. 252-279.

- (1997): «Actitudes empresariales ante las inversiones en tecnología: el caso de Altos Hornos de Bilbao (1880-1899)», en Seminario de Historia Económica: Tecnología, empresa e industrialización en España (siglos XIX y XX). Soria: Fundación Duques de Soria.

Fusi, J. P. (1975): Política obrera en el País Vasco, 1880-1923. Madrid: Turner.

Galarza, A. (1996): Los orígenes del empresariado vasco. Creación de sociedades e inversión de capital, Bilbao (1850-1882). Bilbao: Beitia.

Goenaga, I. (1883): «El hierro de Vizcaya». Revista Minera y Metalúrgica, XXXIV, pp. 356-357.

GuIARD, T. (1968) [1917]: La industria naval vizcaína (Anotaciones históricas y estadísticas desde sus orígenes hasta 1917). Bilbao: Biblioteca Vascongada Villar.

HÉBERT, R. F. y Link, A. N. (1982): The Entrepreneur. Mainstream Views and Radical Critiques. Nueva York: Praeger Publishers.

HeERTJe, A. (1988): «Schumpeter and Technical Change», en H. Hanusch (ed.), Evolutionary Economics. Applications of Schumpeter's Ideas. Cambridge: Cambridge University Press, pp. 71-89.

Houpt, S. y Rojo Cajigal, J. C. (1998): «El origen de los astilleros del norte, 1872-1914», en S. Houpt y J. M. Ortiz-Villajos (eds.), Astilleros Españoles, 1872-1998. La construcción naval en España. Madrid: LID. Cap. II, pp. 63-92.

Marcos VoÑas, C. (1988): «Implicaciones políticas de Astilleros del Nervión», en II Congreso Mundial Vasco. Historia de Euskal Herria. Vitoria, Tomo V, pp. 123-132. 
Messori, M. (1983): «Storia e teoria economica: Schumpeter, Keynes e il ciclo del capitale», en M. Messori (ed.), Il mondo contemporaneo. Questioni di metodo. Florencia: Universidad de Florencia.

- (1984): «Il credito nel modello de Schumpeter», en M. Messori (ed.), Atti del convegno: Società, sviluppo, impressa. Nel centenario della nascita di J. A. Schumpeter. Milán: Franco Angeli.

Morishima, M. y Catephores G. (1988): «Anti-Say's Law Versus Say’s Law: a change in paradigm», en H. Hanusch (ed.), Evolutionary Economics. Applications of Schumpeter's Ideas. Cambridge: Cambridge University Press, pp. 23-53.

Ossa Echaburu, R. (1969): El Bilbao del Novecientos. Riqueza y poder de la Ría (19001923). Bilbao: Biblioteca Vascongada Villar.

Otazu, A. de (1987): Los Rothschild y sus socios españoles (1820-1850). Madrid: Otazu Hermanos Ediciones.

Perroux, F. (1965): La Pensée Economique de Joseph Schumpeter. París: Librairie Droz.

Puerta Rueda, N. de la (1994): El Puerto de Bilbao como reflejo del desarrollo industrial de Vizcaya, 1857-1913. Bilbao: Autoridad Portuaria.

Rodríguez González, A. R. (1988): Política naval de la Restauración (1875-1898). Madrid: Editorial San Martín.

Ronstadt, T. (1986): «Exit, Stage Left: Why Entrepreneurs End Their Entrepreneurial Careers Before Retirement». Journal of Business Venturing 1 (3), pp. 323-38.

Ruiz AzúA, E. (1976): El sitio de Bilbao en 1874. Estudio del comportamiento social de una ciudad en guerra. Bilbao: Editorial La Gran Enciclopedia Vasca.

Schumpeter, J. A. (1944): Teoría del desenvolvimiento económico. México: Fondo de Cultura Económica.

- (1968): «La respuesta creadora en la historia económica», en Ensayos. Vilassar de Mar: Oikos-Tau, pp. 255-272.

- (2002): Ciclos económicos. Análisis teórico, histórico y estadístico del proceso capitalista. Zaragoza: Prensas Universitarias de Zaragoza.

SweEzy, P. M. (1968): El presente como historia. Madrid: Tecnos.

TORREs, E. (1998): Ramón de la Sota, 1857-1936. Un empresario vasco. Madrid: LID.

TORTELlA, T. (2000): Una guía de fuentes sobre inversiones extranjeras en España (17801914). Madrid: Archivo del Banco de España.

VAldAliso, J. M. (1988): «Grupos empresariales e inversión de capital en Vizcaya, 18861913». Revista de Historia Económica VI (1), pp. 11-40.

- (1991): Los navieros vascos y la marina mercante en España, 1860-1935. Una historia económica. Bilbao: IVAP.

— (1996): «Las empresas navieras españolas: estructura y financiación (c.1860-1935)», en F. Comín y P. Martín Aceña (eds.), La empresa en la historia de España. Madrid: Civitas, pp. 303-323.

Vence DeZa, X. (1995): Economía de la innovación y del cambio tecnológico. Madrid: Siglo XXI.

WolfF, J. (1982): Les Grandes Oeuvres Economiques (Vol. 4). París: Éditions Cujas.

Ybarra Bergé, J. (1947): Política nacional en Vizcaya. De la Restauración a la República. Madrid: Instituto de Estudios Políticos.

Ybarra Ybarra, J. (2002): Nosotros, los Ybarra. Vida, economía y sociedad (1744-1902). Barcelona: Tusquets. 